\title{
Activation of galanin and cholecystokinin receptors in the lumbosacral spinal cord is required for ejaculation in male rats
}

\author{
Natalie Kozyrev ${ }^{1,2}$ and Lique M. Coolen ${ }^{1,2,3,4}$ \\ ${ }^{1}$ Department of Anatomy and Cell Biology, Western University, London, ON, Canada \\ ${ }^{2}$ Department of Physiology, University of Michigan, Ann Arbor, MI, USA \\ ${ }^{3}$ Department of Neurobiology and Anatomical Sciences, University of Mississippi Medical Center, Jackson, MS, USA \\ ${ }^{4}$ Department of Physiology and Biophysics, University of Mississippi Medical Center, 2500 North State Street, Jackson, MS \\ 39216, USA
}

Keywords: autonomic, copulation, sexual behavior, spinal cord, spinal ejaculation generator

Edited by Michel Barrot

Received 14 September 2016, revised 15 December 2016, accepted 17 December 2016

\begin{abstract}
The spinal ejaculation generator is comprised of lumbar spinothalamic (LSt) cells and their axonal projections to autonomic and motor neurons in the lumbosacral spinal cord. LSt cells regulate ejaculatory reflexes by release of neuropeptides that are coexpressed in their axons, as previously demonstrated for gastrin-releasing peptide and enkephalin. Here, the role of two other neuropeptides co-expressed in LSt cells for ejaculatory reflexes is demonstrated: galanin and cholecystokinin (CCK). Adult male rats were anesthetized, spinalized, and received intrathecal infusions of galanin receptor antagonist Galantide (1 or $10 \mathrm{nmol}$ ) or CCK receptor antagonist proglumide (71 or $714 \mathrm{nmol})$. The dorsal penile nerve (DPN) was electrically stimulated to trigger ejaculatory reflexes and seminal vesicle pressure (SVP) and rhythmic contractions of the bulbocavernosus muscle (BCM) were analyzed as parameters of emission and expulsion respectively. Treatment with galanin or CCK antagonists significantly reduced SVP increases and BCM bursting, demonstrating that galanin and CCK are required for ejaculation. Next, anesthetized, spinalized males received intrathecal infusions of galanin $(0.15$ or $0.3 \mathrm{nmol})$ or $\mathrm{CCK}_{(26-33)}(4.35 \mathrm{nmol})$ and effects on subthreshold DPN stimulations were determined. Intrathecal infusions of galanin or CCK facilitated ejaculatory reflexes induced by subthreshold DPN stimulation in all animals, but did not trigger ejaculatory reflexes in the absence of DPN stimulation. Together, these results demonstrate that galanin and CCK both act in the spinal ejaculation generator to regulate ejaculation. However, effects of galanin and CCK were dependent on DPN stimulation, suggesting that these neuropeptides may act in concert with other LSt co-expressed neuropeptides.
\end{abstract}

\section{Introduction}

In male mammals, ejaculation is a reflex controlled by the spinal ejaculation generator, which controls ejaculation through a complex co-ordination of the sympathetic, parasympathetic, and motor components with sensory inputs during sexual activity (Coolen et al., 2004; Coolen, 2005; Veening \& Coolen, 2014; Clement \& Giuliano, 2016). Ejaculation is defined as the forceful discharge of seminal contents from the urethral meatus and consists of two phases: emission and expulsion (Coolen et al., 2004; Coolen, 2005; Veening \& Coolen, 2014; Clement \& Giuliano, 2016). Emission refers to the secretion of seminal fluids from the prostate, seminal vesicles, and vas deferens and these processes are under the control of parasympathetic preganglionic neurons in the sacral parasympathetic nucleus

Correspondence: Lique M. Coolen, ${ }^{4}$ Department of Physiology and Biophysics, as above.

E-mail: lcoolen@umc.edu
(SPN) in the upper sacral spinal cord and under control of sympathetic preganglionic neurons in the intermediolateral cell column (IML) and central autonomic nucleus (CAN) in the thoracolumbar spinal cord (Allard et al., 2005; Young et al., 2009; Giuliano, 2011). The expulsion component is characterized by rhythmic contractions of the striated perineal muscles, including the muscle of the bulbocavernosus (BCM), accompanied by the forceful expulsion of semen from the urethral meatus (Gerstenberg et al., 1990; Holmes \& Sachs, 1991; Holmes et al., 1991). Motor neurons that control the rhythmic contraction of the BCM are located in the spinal nucleus of the bulbocavernosus (SNB) in the lumbosacral spinal cord in male rats (Schroder, 1980; McKenna \& Nadelhaft, 1986). The sensory inputs to the spinal ejaculation generator are primarily relayed via the dorsal penile nerve (DPN) and stimulation of the DPN triggers ejaculatory reflexes (Staudt et al., 2010, 2011, 2012). The pivotal component of the spinal ejaculation generator is composed of a population of 
interneurons referred to as lumbar spinothalamic (LSt) cells, and located in lamina 10 and the medial portion of lamina 7 of lumbar segments 3 and 4 (L3-4). LSt cells are essential for ejaculation as LSt cell-specific lesions ablate ejaculatory reflexes and behavior (Truitt \& Coolen, 2002; Staudt et al., 2012). It is hypothesized that LSt cells transform sensory signals associated with the summation of coitus and conveyed by the DPN, into motor and secretory outputs to trigger emission and expulsion (Truitt et al., 2003; Staudt et al., 2010, 2011). LSt cells co-express several neuropeptides including gastrin releasing peptide (GRP), enkephalin, galanin, and cholecystokinin (CCK) (Nicholas et al., 1999; Coolen et al., 2003; Kozyrev et al., 2012). Therefore, we hypothesize that these neuropeptides are released from LSt cell axon terminals onto preganglionic sympathetic (IML and CAN), parasympathetic (SPN), and motor (SNB) neurons to modulate ejaculatory reflexes. Indeed, our laboratory has recently revealed a critical role for GRP and enkephalin within the spinal ejaculation generator in male rats (Kozyrev et al., 2012; Kozyrev \& Coolen, 2015). It was discovered that intrathecal infusions of the GRP antagonist RC-3095, mu opioid receptor antagonists CTOP, and delta opioid receptor TIPP, severely disrupted ejaculatory reflexes in anesthetized and spinalized male rats (Kozyrev et al., 2012; Kozyrev \& Coolen, 2015). Conversely, intrathecal infusion of the GRP agonist $\mathrm{GRP}^{2029}$ or mu opioid receptor agonist DAMGO triggered ejaculatory reflexes in male rats. In addition, intrathecal infusion of $\mathrm{GRP}^{2029}$, DAMGO, or delta receptor agonist deltorphin II, facilitated ejaculatory reflexes following subthreshold levels of DPN stimulation insufficient to trigger ejaculatory reflexes in control animals (Kozyrev et al., 2012; Kozyrev \& Coolen, 2015). However, the roles of galanin and CKK for ejaculation are currently unknown, even though LSt cells were first described based on the expression of these neuropeptides (Truitt \& Coolen, 2002; Coolen et al., 2003) Moreover, galanin immunoreactivity has been demonstrated in the human spinal ejaculation generator (Chéhensse et al., 2016).

The purpose of the current study was to test the hypothesis that galanin and CCK neuropeptides released by LSt axon terminals onto their target regions, are critical for triggering the emission and expulsion components of ejaculation. The current study aimed to investigate the individual contributions of galanin and CCK receptor activation in the control of emission and expulsion reflexes induced by electrical stimulation of the DPN in anesthetized and spinalized male rats.

\section{Materials and methods}

\section{Animals}

For these experiments, adult male Sprague Dawley rats (225-250 g) were obtained from Charles River (Wilmington, MA, USA) and housed in pairs in standard housing cages on a reverse 12-hour light/dark cycle with lights off at 09:00 h. Food and water were available ad libitum. All procedures were approved by the University Committee on Use and Care of Animals at the University of Michigan and conformed to the guidelines outlined by the National Institutes of Health.

\section{Surgical procedures}

Procedures were identical to our previously described studies (Staudt et al., 2010, 2011, 2012; Kozyrev et al., 2012, 2016; Kozyrev \& Coolen, 2015). Sexually naive adult male rats were deeply anesthetized with urethane $(1.5 \mathrm{~g} / \mathrm{kg}$, i.p.), a laminectomy was performed between the sixth and the eighth thoracic spinal segments and a complete transaction of the spinal cord was performed at the same spinal level. Next, the bulbocavernosus muscle (BCM) and the dorsal penile nerve (DPN) were surgically exposed and the surrounding connective tissue was removed. Subsequently, silver recording electrodes, attached to the PowerLab/7SP Data Acquisition System (AD Instruments, Inc., Colorado Springs, CO, USA) were inserted bilaterally into the BCM and a ground electrode was placed into the muscle of the right thigh in preparation for electromyographic (EMG) recordings. Additionally, the right seminal vesicle was exposed by coeliotomy for the purpose of measuring and recording seminal vesicle pressure (SVP), a marker of the emission component of ejaculation (Clement et al., 2008; Giuliano et al., 2010; Kozyrev et al., 2012, 2016; Kozyrev \& Coolen, 2015). SVP was measured with a pressure catheter (AD Instruments Inc., model number: SPR-671(1.4 F, Single, Straight, $15 \mathrm{~cm}, \mathrm{NY}$ ) attached to a catheter interface cable (AD Instruments Inc., model number: AEC-IOD) and connected to a Bridge AMP (AD Instruments Inc.). The pressure catheter was carefully inserted into the lumen of the seminal vesicle and secured in place prior to recording. In preparation for stimulation of the DPN, a bipolar stimulating electrode connected to the SD9 Square Pulse Stimulator (Grass Technologies, West Warwick, RI, USA) was positioned directly above the DPN. Initial stimulation of the DPN was performed immediately after spinal cord transection in order to verify that the spinal cord transection is complete, as demonstrated by rhythmic bursting of the BCM and simultaneous SVP increases. Initial electrical stimulation of the DPN comprised square wave pulses of $1 \mathrm{~ms}$ duration, $4 \mathrm{~V}$ at $60 \mathrm{~Hz}$ for $10 \mathrm{~s}$. These established DPN stimulation parameters reliably trigger rhythmic bursting of the BCM, corresponding to the expulsion phase of ejaculation, in all saline-treated control animals (Giuliano et al., 2010; Staudt et al., 2010, 2011, 2012; Kozyrev et al., 2012, 2016; Kozyrev \& Coolen, 2015). In addition, spinal cords were removed after completion of all the experiments and the complete separation of the spinal cord at mid thoracic levels was confirmed anatomically. Pharmacological experiments began two hours after spinal cord transection in order to allow the acute effects of spinal cord transection to subside (Staudt et al., 2010). Next, a small incision was made in the dura mater at the site of the laminectomy and a polyethylene catheter (Caly-Adams PE-10, Parsippany, NJ, USA) was carefully inserted into the subarachnoid space until the open end reached the 3rd lumbar-4th lumbar (L3-L4) spinal segments.

\section{Experimental designs}

\section{General design}

Each animal received two "Testing Trials", which consisted of a first trial during which all animals received intrathecal infusions of saline and recording of BCM EMG and SVP, followed by stimulations of the DPN and recording of BCM EMG and SVP. In a subsequent second trial, all animals received intrathecal infusions of galanin or CCK antagonists or agonists and recording of BCM EMG and SVP, followed by stimulations of the DPN and recording of BCM EMG and SVP. Thus, this first testing trail served as a control trail (Trial 1; saline trial and the second trial thus served as the experimental trial (Trial 2; drug trial). Our previous publications have demonstrated that saline infusions or repeated DPN stimulations do not affect parameters of ejaculatory reflex (Kozyrev et al., 2012, 2016; Kozyrev \& Coolen, 2015).

\section{Intrathecal infusions of galanin or CCK antagonists}

In Trial 1 (saline trial), $10 \mu \mathrm{L}$ of saline was infused in each animal through the polyethylene catheter to bathe the entire 
lumbosacral spinal cord and BCM EMG activity was recorded for $25 \mathrm{~min}$. Following the saline infusion, the DPN was stimulated at 30 and $60 \mathrm{~Hz}$ in a counterbalanced order, with 5-min rest periods between stimulations. These stimulation parameters reliably trigger ejaculatory reflexes in control male rats (Staudt et al., 2010, 2011, 2012; Kozyrev et al., 2012, 2016; Kozyrev \& Coolen, 2015). After each DPN stimulation, BCM EMG and SVP were recorded for a period of $90 \mathrm{~s}$, corresponding to the duration of a representative ejaculatory reflex triggered by DPN stimulation in male rats (Staudt et al., 2010, 2011, 2012; Kozyrev et al., 2012, 2016; Kozyrev \& Coolen, 2015). The entire procedure was repeated one hour later in the same animals, which now received drug treatment (Trial 2; drug trial), consisting of either a $10 \mu \mathrm{L}$ infusion of the galanin antagonist galantide or the CCK antagonist proglumide. In total, three antagonist experiments were conducted in three separate groups of animals. To determine the effects of galantide, in a first experiment, males received one of two doses of galantide (1 nmol, $n=7 ; 10$ nmol, $n=8$; Phoenix Pharmaceuticals Inc. USA, Burlingame, CA, USA), and the effects on BCM EMG, but not SVP, were recorded for $25 \mathrm{~min}$. In a second experiment, effects of one dose of galantide ( $10 \mathrm{nmol}, n=6)$ were determined for both BCM EMG and SVP. In the third experiment, animals received one of two doses of the CCK antagonist proglumide (71 nmol, $n=6$; $714 \mathrm{nmol}, n=6$; Sigma-Aldrich Corp. St. Louis, MO, USA). BCM EMG and SVP were recorded for $25 \mathrm{~min}$ after drug infusion. At $25 \mathrm{~min}$ after antagonist infusion, the DPN was stimulated at 30 and $60 \mathrm{~Hz}$ in a counterbalanced order with 5 min between stimulations, and concurrent recordings of $90 \mathrm{~s}$ for BCM EMG and SVP after each of the DPN stimulations (Trial 2; drug trial).

\section{Intrathecal infusions of galanin or CCK}

Male rats were anesthetized, spinalized, and prepared as described above and a similar experimental design was used. In Trial 1 (saline trial), all male rats received $10 \mu \mathrm{L}$ intrathecal infusions of $0.9 \%$ saline and BCM EMG and SVP were recorded for 10 min after infusion. Next, the DPN was stimulated at 5, 10, 30, and $60 \mathrm{~Hz}$ in a randomized and counterbalanced order with $5 \mathrm{~min}$ intervals between stimulations, and BCM EMG and SVP were recorded for a 90-s duration following each stimulation (Trial 1, saline trial). The 5 and $10 \mathrm{~Hz}$ stimulation frequencies do not normally trigger ejaculatory reflexes in control male rats and are subthreshold stimulations. Therefore, the use of these stimulations allows for the detection of facilitatory effects of the receptor agonists (Kozyrev et al., 2012; Kozyrev \& Coolen, 2015). One hour following the final DPN stimulation, the procedure was repeated in the same animals, which now received $10 \mu \mathrm{L}$ intrathecal infusions of galanin or CCK (Trial 2; drug trial). In total, three separate experiments were conducted. The effects of galanin were tested in two separate experiments. In the first experiment, rats received one of two doses of galanin $(0.15 \mathrm{nmol}, n=6$ or $0.3 \mathrm{nmol}, n=7$; Bachem Americas, Inc. Torrance, CA, USA) and BCM EMG, but not SVP, was recorded. In the second experiment, rats received galanin $(0.3 \mathrm{nmol}$, $n=7$ ) and both BCM EMG and SVP recordings were conducted. In the third experiment, rats received CCK [26-33 (sulfated), 4.35 nmol; $n=8$; Phoenix Pharmaceuticals Inc. USA, Burlingame, CA, USA] and BCM EMG and SVP were recorded for $10 \mathrm{~min}$ after infusion. Next, $10 \mathrm{~min}$ after agonist infusions, the DPN was stimulated at 5, 10,30, and $60 \mathrm{~Hz}$ in a counterbalanced order and BCM EMG and SVP were recorded for $90 \mathrm{~s}$ after each DPN stimulation.

\section{Analysis of BCM EMG and SVP}

\section{General criteria}

Analyses were performed as described in our previous studies (Staudt et al., 2010, 2011, 2012; Kozyrev et al., 2012, 2016; Kozyrev \& Coolen, 2015). Analysis of BCM EMG and SVP recordings spanned $25 \mathrm{~min}$ or $10 \mathrm{~min}$ after infusion of the antagonist or agonist, respectively, and $90 \mathrm{~s}$ after every DPN stimulation. The numbers of BCM events, bursts, and SVP increases were analyzed using LabChart 7.35 (AD Instruments Inc.) as in our previous publications (Staudt et al., 2010, 2011, 2012; Kozyrev et al., 2012, 2012; Kozyrev \& Coolen, 2015). Additionally, criteria for BCM events, bursts, and SVP increases were set as in our previous papers. Events were defined as any increase above baseline activity; bursts were defined by grouping of 10 or more consecutive events without return to baseline between events, and SVP increases were defined as an increase above baseline. Data for all animals were included in the analyses.

\section{Statistical analyses antagonist studies}

The effects of antagonist treatments on the numbers of events, bursts and SVP increases were compared within animals (between trial 1 and trial 2 within the same group of animals for each of the drug doses) and between treatment groups (between different doses within trial 1 and again within trial 2), for the 30 and $60 \mathrm{~Hz}$ stimulations separately. None of the animals demonstrated any response to antagonist infusions, hence data were not further analyzed for this infusion period. For these analyses, a two-way repeated ANOvA was used (factors: Testing Trial and Drug dose) with Holm-Sidak pairwise comparisons for post hoc tests. Tests for normal distribution and equal variance were conducted for all data and a $95 \%$ confidence level was utilized for all tests.

\section{Statistical analyses agonist studies}

The effects of agonist infusions on the numbers of events, bursts, and SVP increases were compared within animals (between trial 1 and trial 2, within the same group of animals for each of the drug doses) and between treatment groups (between different doses within trial 1 and again within trial 2), separately for each stimulation setting: Infusion, 5, 10, 30, and $60 \mathrm{~Hz}$ ). For these analyses, a two-way repeated ANOvA was used (factors: Trial and DPN stimulation) and Holm-Sidak pairwise comparisons for post hoc tests. In addition, the effects of 30 and $60 \mathrm{~Hz}$ stimulation frequencies on the numbers of BCM events, bursts, and SVP increases were compared to responses during infusion using Student $t$-tests. Tests for normal distribution and equal variance were conducted for all data and a 95\% confidence level was utilized for all tests.

\section{Results}

\section{Galantide suppressed BCM activity}

In the first experiment, the effects of two dosages of the galanin antagonist galantide on BCM events and bursts were determined (Fig. 1). Galantide significantly suppressed DPN stimulationinduced ejaculatory reflexes at both 30 and $60 \mathrm{~Hz}$ stimulation frequencies as shown in the reduced numbers of BCM events, and bursts. 
Trial 1: Saline-galantide $1 \mathrm{nmol}$

口 Trial 1: Saline-galantide $10 \mathrm{nmol}$
Trial 2: Galantide $1 \mathrm{nmol}$

- Trial 2: Galantide $10 \mathrm{nmol}$
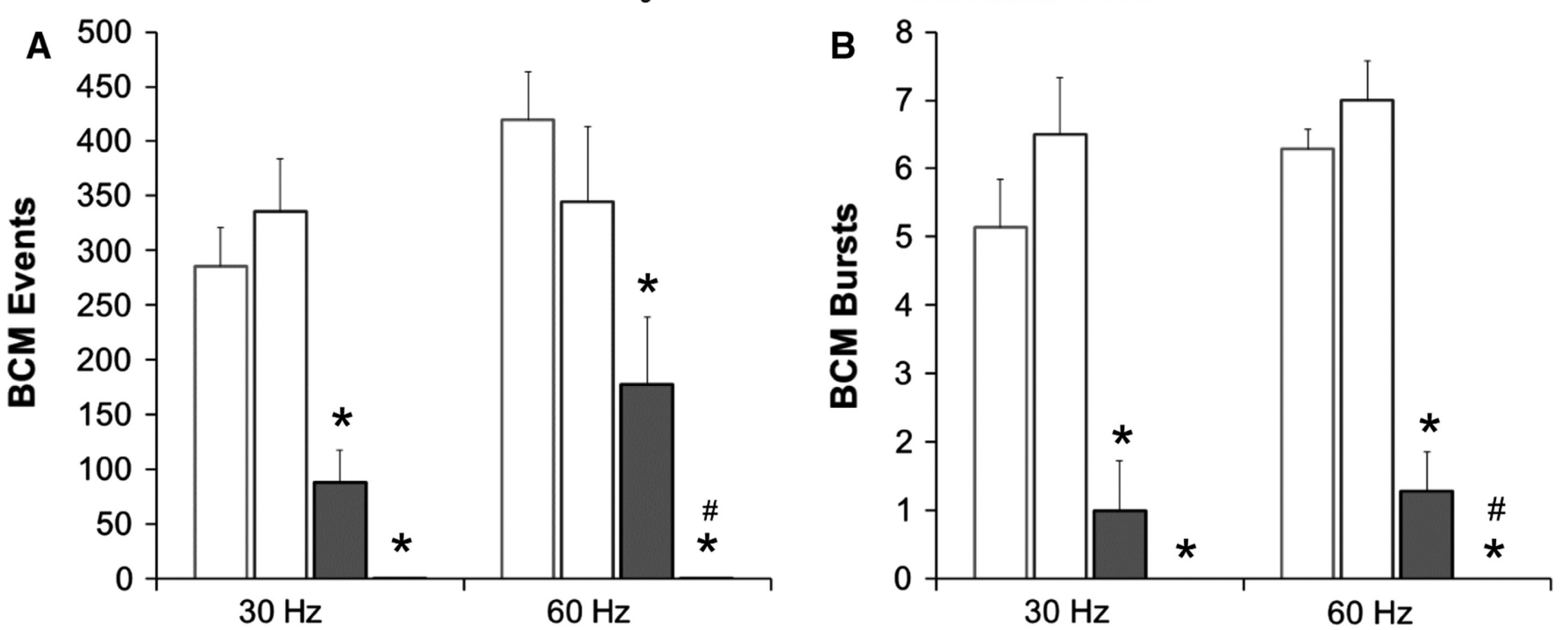

C

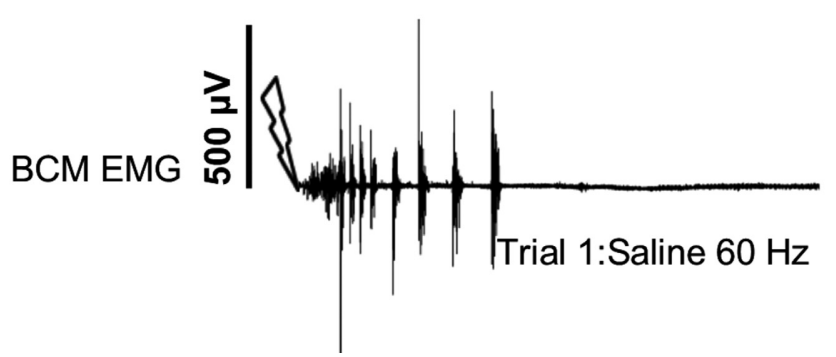

D

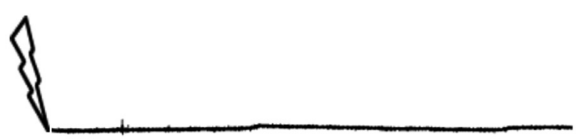

Trial 2:Galantide (10 nmol): $60 \mathrm{~Hz}$

FIG. 1. Effects of galantide on numbers of bulbocavernosus muscle (BCM) events and bursts in male rats. Quantitative analyses and accompanying electromyographic (EMG) traces of BCM events and bursts following intrathecal infusions of galantide. Quantitative analysis of BCM events (A) and bursts (B) in response to 30 and $60 \mathrm{~Hz}$ dorsal penile nerve (DPN) stimulations following infusions of saline in trial 1 (control trial) or one of two doses of galantide (1 or $10 \mathrm{nmol}$ ) in trial 2 (drug trial). EMG traces of $90 \mathrm{~s}$ duration following $60 \mathrm{~Hz}$ DPN stimulation (arrow) after an intrathecal infusion of saline (C: control trial) and galantide (D: same animals as in C). ${ }^{*}$ denotes significant differences from trial 1 within the same treatment group, while \# indicates significant differences between treatment groups within the same testing trial.

\section{BCM events}

There were main effects of testing trial (trail 1 vs. trial 2) on the numbers of BCM events for both $30 \mathrm{~Hz}\left(F_{1,13}=50.905 ; P<0.001\right)$ and $60 \mathrm{~Hz}$ stimulation frequencies $\left(F_{1,13}=30.213 ; P<0.001\right.$; Fig. $1 \mathrm{~A}$, $\mathrm{C}$ and D). Post hoc analyses revealed that animals treated with either dose of galantide during trial 2 (drug trial) had significantly decreased $\mathrm{BCM}$ events in response to 30 and $60 \mathrm{~Hz}$ DPN stimulations compared to trial 1 (saline trial; $30 \mathrm{~Hz}: P=0.003$ (1 nmol); $P<0.001$ $(10 \mathrm{nmol}) ; \quad 60 \mathrm{~Hz}: \quad P=0.008 \quad(1 \mathrm{nmol}) ; \quad P<0.001 \quad(10 \mathrm{nmol})$; Fig. 1A, C and D). In addition, animals treated with the higher dose of galantide during trial 2 displayed significantly fewer BCM events in response to $60 \mathrm{~Hz}$ DPN stimulation frequency compared to saline treatment in trial 1 [saline trial; $P=0.022(10 \mathrm{nmol})$; Fig. $1 \mathrm{~A}, \mathrm{C}$ and D]. None of these effects were attributable to pre-existing group differences, as in trial 1 when all animals received saline, there were no significant differences in the numbers of $\mathrm{BCM}$ events in response to either 30 or $60 \mathrm{~Hz}$ DPN stimulations between groups (Fig. 1A).

\section{BCM bursts}

The effects of galantide on BCM bursts paralleled the effects on BCM events (Fig. 1B-D). There were main effects of testing trial (trial 1 vs. trial 2) on the numbers of BCM bursts for both $30 \mathrm{~Hz}$
$\left(F_{1,13}=100.213 ; \quad P<0.001\right) \quad$ and $\quad 60 \mathrm{~Hz} \quad\left(F_{1,13}=218.400 ;\right.$ $P<0.001$ ) stimulation frequencies (Fig. 1B). Specifically, male rats treated with either dose of galantide during trial 2 (drug trial) demonstrated significantly fewer $\mathrm{BCM}$ bursts compared to trial 1 (saline trial) [30 Hz: $P<0.001(1 \mathrm{nmol}) ; P<0.001(10 \mathrm{nmol}) ; 60 \mathrm{~Hz}$ : $P<0.001$ (1 nmol); $P<0.001(10 \mathrm{nmol})$; Fig. 1B-D]. In addition, there were significant interactions between factors of testing trial and drug dosage on the number of BCM bursts for both $30 \mathrm{~Hz}$ $\left(F_{1,13}=4.916 ; P=0.045\right)$ and $60 \mathrm{~Hz}\left(F_{1,13}=6.067 ; P=0.029\right)$ stimulation frequencies. Post hoc analyses demonstrated that male rats treated with the higher dose of galantide during trial 2 (drug trial) had significantly fewer BCM bursts in response to $60 \mathrm{~Hz}$ DPN stimulation frequency [trial 2: $P=0.041(10 \mathrm{nmol})]$ compared to trial 1 (saline trial; Fig. 1B-D). There were no significant differences in the numbers of BCM bursts after 30 or $60 \mathrm{~Hz}$ DPN stimulation within trial 1 (saline trial), indicating that differences in trial 2 (drug trial) were due to the effects of galantide (Fig. 1B).

\section{Galantide suppressed seminal vesicle pressure and BCM activity}

The effects of galantide on SVP increases, a marker of the emission component of ejaculation, were tested in a second experiment, using 

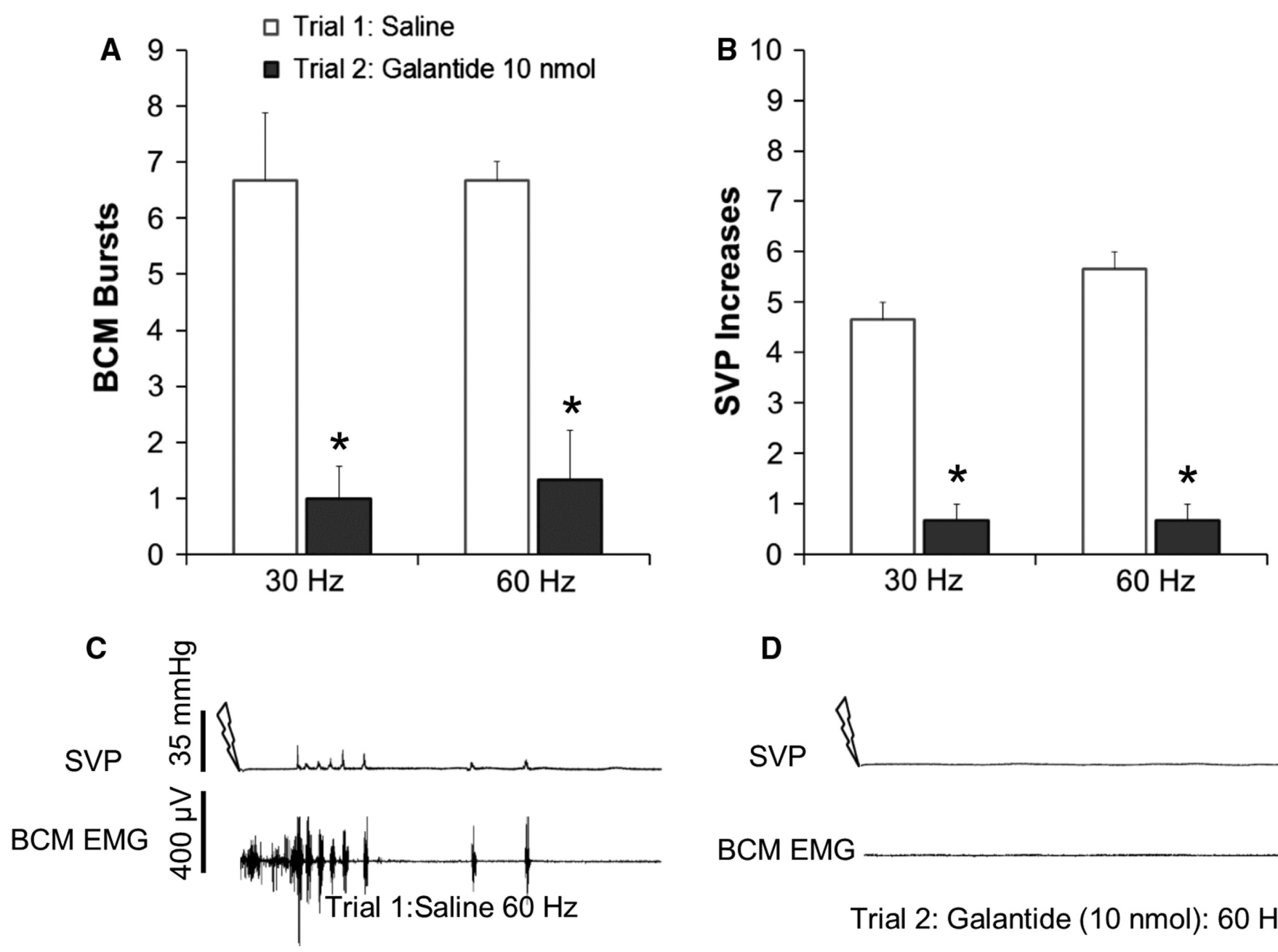

D

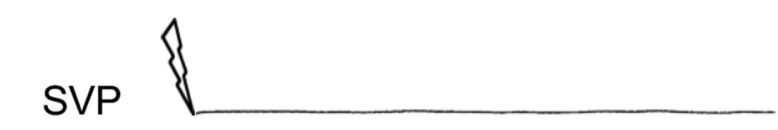

BCM EMG

Trial 2: Galantide (10 nmol): $60 \mathrm{~Hz}$

FIG. 2. Effects of galantide on the numbers of bulbocavernosus muscle (BCM) bursts and seminal vesicle pressure (SVP) increases in male rats. Quantitative analyses and accompanying electromyographic (EMG) traces of BCM bursts and SVP increases following intrathecal infusions of galantide. Quantitative analysis of BCM bursts (A) and SVP increases (B) in response to 30 and $60 \mathrm{~Hz}$ dorsal penile nerve (DPN) stimulations following infusions of saline in trial 1 (control trial) or galantide $(10 \mathrm{nmol})$ in trial 2 (drug trial). EMG and concurrent SVP traces of $90 \mathrm{~s}$ duration following $60 \mathrm{~Hz}$ DPN stimulation (arrow) after an intrathecal infusion of saline (C: control trial) and galantide (D: same animals as in C). * denotes significant differences from trial 1 (control trial).

a separate group of animals in which BCM EMG and SVP were recorded simultaneously following intrathecal infusion of the higher dose of galantide $(10 \mathrm{nmol})(n=6$; Fig. 2). The attenuating effects of galantide on BCM events and bursts were replicated and paralleled by significant decreases in the numbers of SVP increases (Fig. 2). There were main effects of testing trial (trial 1 vs. trial 2) on the numbers of BCM events $\left(F_{1,5}=30.227 ; P=0.003\right.$; data not shown), BCM bursts $\left(F_{1,5}=53.382 ; P<0.001\right)$, and SVP increases $\left(F_{1,5}=110.401 ; P<0.001\right)$. Post hoc analyses revealed that male rats treated with galantide in trial 2 (drug trial) showed significantly fewer numbers of BCM events, bursts, and SVP increases than in trial 1 (saline trial) for both $30 \mathrm{~Hz}$ [events: $P=0.004$ (data not shown); bursts: $P<0.001$ (Fig. 2A); SVP: $P<0.001$; (Fig. 2B)] and $60 \mathrm{~Hz}$ [events: $P=0.001$ (data not shown); bursts: $P<0.001$ (Fig. 2A, C and D); SVP: $P<0.001$; (Fig. 2B-D)] stimulation frequencies. Even though the attenuating effects of galantide were replicated in this second experiment, the $10 \mathrm{nmol}$ dosage in experiment 2 did not completely suppress all BCM activity in all animals, as in the first experiment. In the second experiment, three to four of six animals showed one to two bursts during the $90 \mathrm{~s}$ recording period after DPN stimulations, whereas in the first experiment, none of the animals showed a single burst. There were no differences in methodology between experiments that explain this slight difference in results. Moreover, the suppression by galantide in the second experiment was severe, as all of the animals showed 5-10 BCM bursts after DPN stimulations during the first trial in which they received saline. Overall, these results confirm that intrathecal galantide suppresses both the emission and expulsion components of ejaculation, indicating that activation of galanin receptors in the lumbosacral spinal cord is required for ejaculatory reflexes in male rats.

\section{Proglumide suppressed ejaculatory reflexes}

The CCK antagonist proglumide dose-dependently disrupted DPN stimulation-induced ejaculatory reflexes in response to 30 and $60 \mathrm{~Hz}$ stimulation frequencies as reflected in the reduced numbers of BCM events, bursts, and SVP increases (Fig. 3).

\section{$B C M$ events}

There were main effects of testing trial (trial 1 vs. trial 2) on the numbers of BCM events (Fig. 3A, D and E) for both $30 \mathrm{~Hz}$ $\left(F_{1,10}=23.289 ; P<0.001\right)$ and $60 \mathrm{~Hz}\left(F_{1,10}=5.446 ; P=0.042\right)$ 

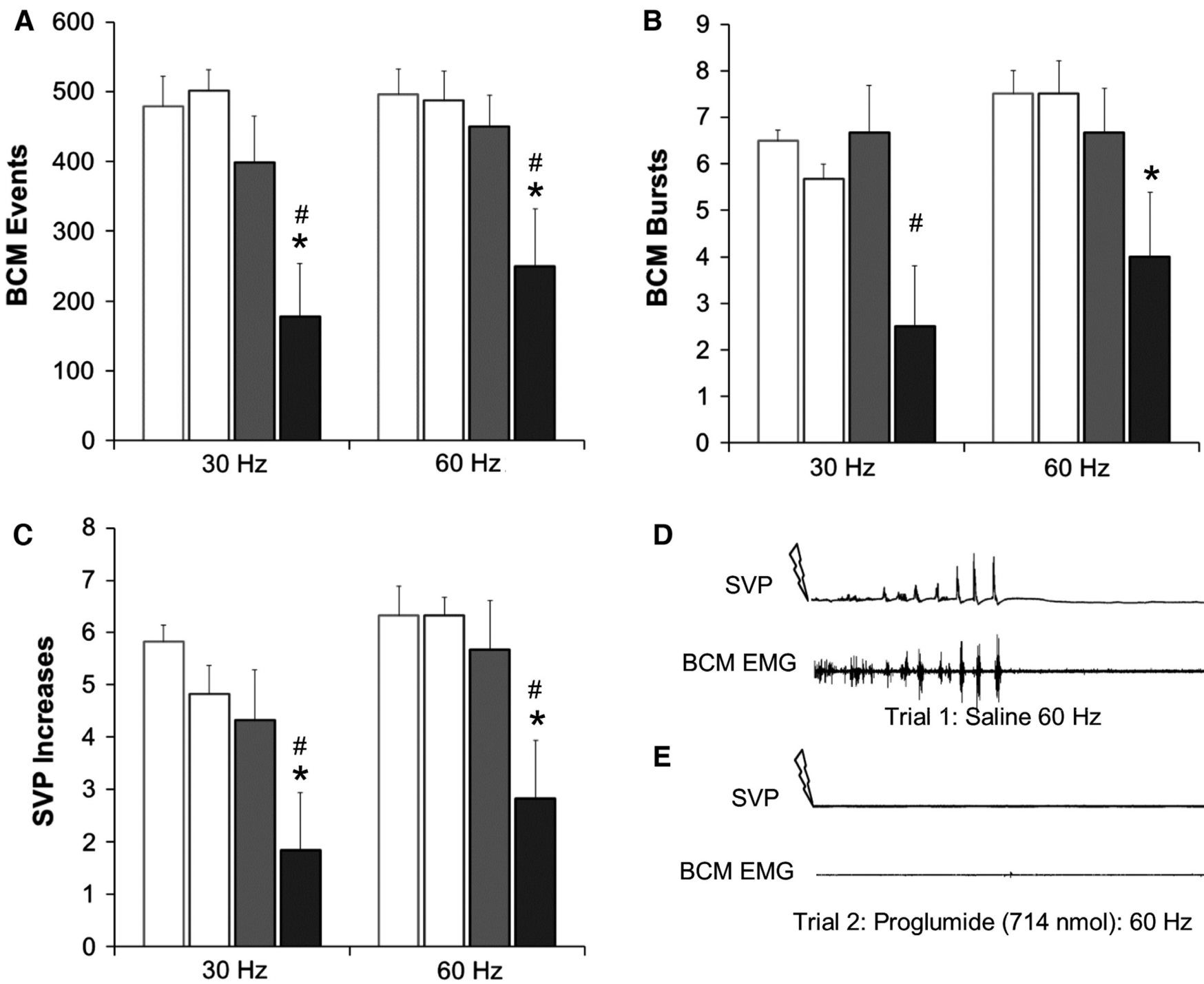

D

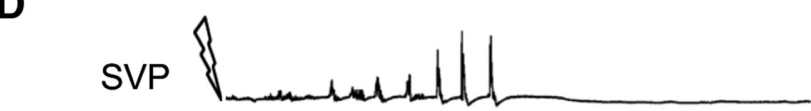

\section{BCM EMG}

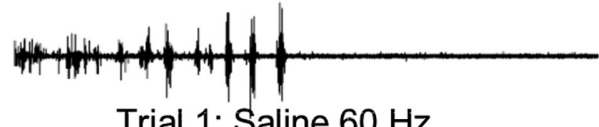

$\mathbf{E}$

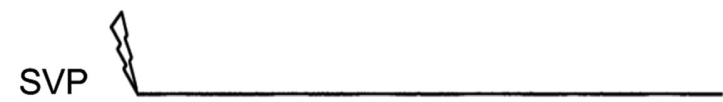

BCM EMG

Trial 2: Proglumide (714 nmol): $60 \mathrm{~Hz}$

FIG. 3. Effects of proglumide on the numbers of bulbocavernosus muscle (BCM) events, bursts, and seminal vesicle pressure (SVP) increases in male rats. Quantitative analyses and accompanying electromyographic (EMG) traces of BCM events, bursts, and SVP increases following intrathecal infusions of proglumide. Quantitative analysis of BCM events (A), bursts (B), and SVP increases (C) in response to 30 and $60 \mathrm{~Hz}$ dorsal penile nerve (DPN) stimulation following infusions of saline in trial 1 (control trial) or one of two doses of proglumide (71 or $714 \mathrm{nmol}$ ) in trial 2 (drug trial). EMG traces of $90 \mathrm{~s}$ duration following $60 \mathrm{~Hz}$ DPN stimulation (arrow) after an intrathecal infusion of saline (D: control trial) and galantide (E: same animals as in C). * denotes significant differences from trial 1 within the same treatment group, while \# indicates significant differences between treatment groups within the same testing trial.

stimulation frequencies. Post hoc analyses revealed that animals treated with the higher $(714 \mathrm{nmol})$ but not the lower $(71 \mathrm{nmol})$ dose of proglumide during trial 2 (drug trial) had significantly decreased BCM events in response to 30 and $60 \mathrm{~Hz}$ DPN stimulation compared to trial 1 (saline trial) [30 Hz: $P<0.001$ (714 nmol); $60 \mathrm{~Hz}: P=0.020$ (714 nmol); Fig. $3 \mathrm{~A}, \mathrm{D}$, and E]. There was also a main effect of drug dosage on the numbers of $\mathrm{BCM}$ events following $60 \mathrm{~Hz}$ DPN stimulation $\left(F_{1,10}=5.025\right.$; $P=0.049)$ and a significant interaction between factors of drug dosage and testing trial on the numbers of BCM events following $30 \mathrm{~Hz}$ DPN stimulation $\left(F_{1,10}=9.846 ; P=0.011\right)$. Post hoc analyses revealed that male rats treated with the higher dose of proglumide during trial 2 (drug trial) displayed significantly fewer BCM events following $30 \mathrm{~Hz}(P=0.015)$ and $60 \mathrm{~Hz}$ DPN stimulation frequencies $(P=0.018)$ compared to animals that received the lower dose of proglumide during trial 2 (Fig. 3A). There were no significant differences in the numbers of $\mathrm{BCM}$ events in response to 30 or $60 \mathrm{~Hz}$ DPN stimulation frequencies between the groups during trial 1 (saline trial), indicating that group differences were due to the effects of different doses of proglumide (Fig. 3A).

\section{BCM bursts}

Similarly, there were main effects of testing trial (trial 1 vs. trial 2) on the numbers of BCM bursts for the $60 \mathrm{~Hz}$ stimulation frequency $\left(F_{1,10}=6.680 ; P=0.027\right)$, but this did not reach statistical significance for the $30 \mathrm{~Hz}$ DPN stimulation. Post hoc analyses revealed that male rats that received infusions of the higher dose $(714 \mathrm{nmol})$ of proglumide during trial 2 (drug trial) displayed significantly fewer 


\section{口 Trial 1: Saline-Galanin $0.15 \mathrm{nmol} \quad \square$ Trial 2: Galanin $0.15 \mathrm{nmol}$ \\ 口 Trial 1: Saline- Galanin $0.3 \mathrm{nmol} \quad$ Trial 2: Galanin $0.3 \mathrm{nmol}$}
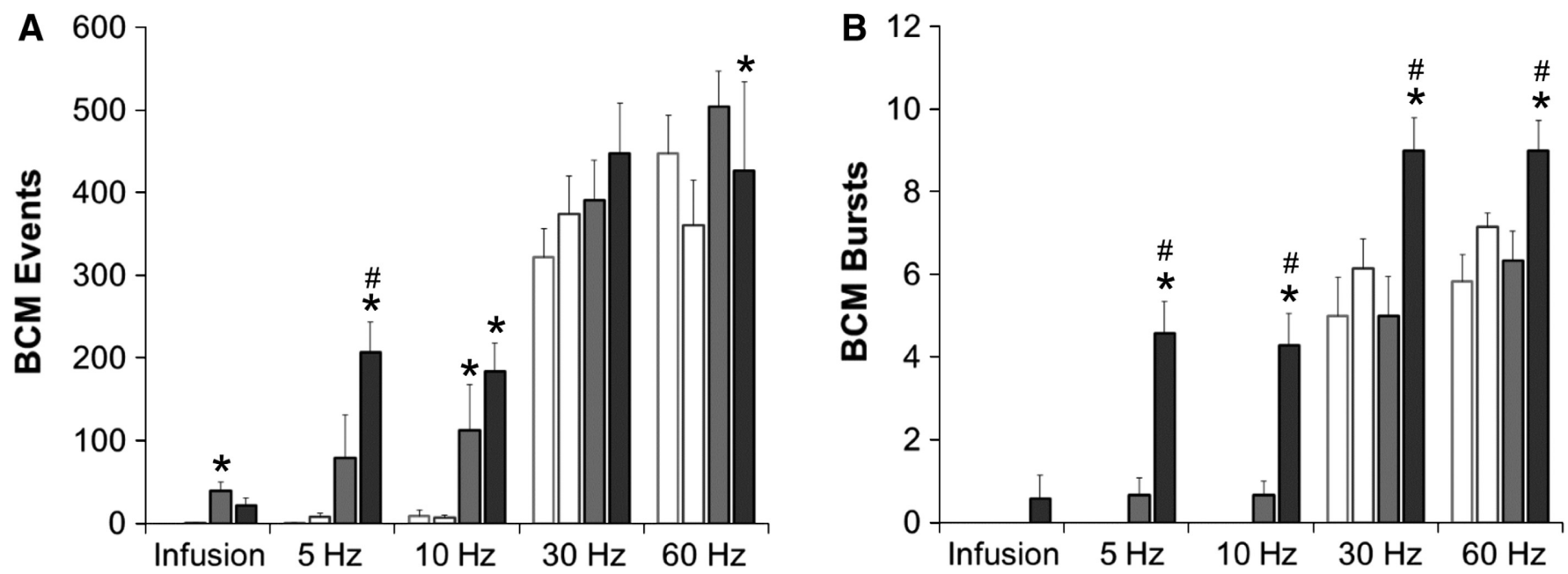

C

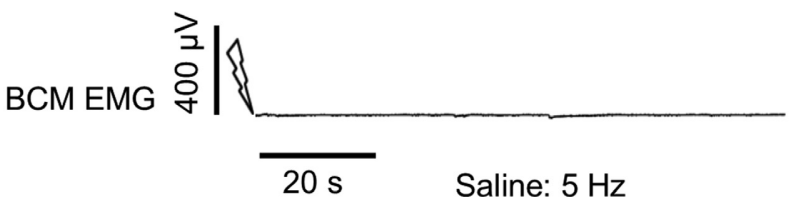

D

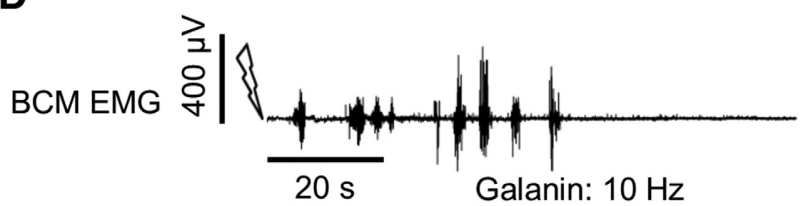

FIG. 4. Effects of galanin on the numbers of bulbocavernosus muscle (BCM) events and bursts in male rats. Quantitative analyses and accompanying electromyographic (EMG) traces of BCM events and bursts following intrathecal infusions of galanin. Quantitative analysis of BCM events (A) and bursts (B) in response to infusion, 5, 10,30, and $60 \mathrm{~Hz}$ dorsal penile nerve (DPN) stimulations (counterbalanced) following infusions of saline in trial 1 (control trial) or one of two doses of galanin $(0.15$ or $0.3 \mathrm{nmol})$ in trial 2 (drug trial). EMG traces of $90 \mathrm{~s}$ duration following $10 \mathrm{~Hz}$ DPN stimulation (arrow) after an intrathecal infusion of saline (C: control trial) and galanin (D: same animals as in C). ${ }^{*}$ denotes significant differences from trial 1 within the same treatment group, while \# indicates significant differences between treatment groups within the same testing trial. Significant effects of 30 and $60 \mathrm{~Hz}$ stimulation frequencies in Trial 1 (white bars) on $\mathrm{BCM}$ events and bursts compared to infusion $(P<0.0001)$ are not marked by a symbol.

BCM bursts than in trial 1 (saline trial), following the $60 \mathrm{~Hz}$ $(P=0.014$; Fig. 3B, D, and E) DPN stimulation frequency. Furthermore, there was a main effect for drug dosage for the $30 \mathrm{~Hz}$ DPN stimulation frequency $\left(F_{1,10}=8.007 ; P=0.018\right)$ and male rats treated with the higher dose $(714 \mathrm{nmol})$ of proglumide showed a significant reduction in the numbers of BCM bursts $(P=0.003)$ compared to male rats treated with the lower dose of proglumide $(71 \mathrm{nmol}$; Fig. 3B). There were no significant differences between the groups in the numbers of BCM bursts following 30 or $60 \mathrm{~Hz}$ DPN stimulations during trial 1 (saline trial; Fig. 3B).

\section{SVP increases}

In addition, intrathecal infusions of proglumide dose-dependently suppressed SVP increases. There were main effects of testing trial (trial 1 vs. trial 2) on the numbers of SVP increases following $30 \mathrm{~Hz} \quad\left(F_{1,10}=10.565 ; \quad P=0.009\right) \quad$ and $60 \mathrm{~Hz} \quad\left(F_{1,10}=6.288\right.$; $P=0.031)$ stimulation frequencies. Post hoc analyses demonstrated that the higher dose $(714 \mathrm{nmol})$ of proglumide significantly reduced numbers of SVP increases compared to trial 1 (saline trial) following $30 \mathrm{~Hz}(P=0.012 ; 714 \mathrm{nmol}$; Fig. $3 \mathrm{C})$ and $60 \mathrm{~Hz}(P=0.014$; 714 nmol; Fig. 3C, D, and E) stimulation frequencies. Furthermore, there was a main effect of dosage during trial 2 (drug trial) whereby animals receiving the higher dose of proglumide $(714 \mathrm{nmol})$ displayed significantly fewer SVP increases compared to the lower dosage, in response to $30 \mathrm{~Hz}(P=0.039$; Fig. $3 \mathrm{C})$ and $60 \mathrm{~Hz}$ $(P=0.021$; Fig. $3 \mathrm{C}, \mathrm{D}$, and E) stimulation frequencies. Finally, there were no differences between groups during trial 1 (saline trial; Fig. 3C).

\section{Galanin facilitated BCM events, bursts, and SVPS}

In the first experiment, effects of two dosages of galanin on BCM events and bursts were determined (Fig. 4). First, in trial 1 (saline trial), it was confirmed that saline infusion, or DPN stimulation at subthreshold stimulation frequencies of 5 and $10 \mathrm{~Hz}$ did not trigger BCM activity (Fig. 4A-C). It was further confirmed that 30 and $60 \mathrm{~Hz}$ DPN stimulation did trigger BCM events and burst (Fig. 4AC; BCM events and bursts: $P<0.0001$ for both groups, for 30 and $60 \mathrm{~Hz}$ stimulation frequencies, compared to saline infusion). Second, in trial 2, galanin was shown to facilitate ejaculatory reflexes.

\section{$B C M$ events}

There were main effects of testing trial (trial 1 vs. trial 2) on the numbers of BCM events for Infusion: $\left(F_{1,11}=17.937 ; P=0.001\right)$; $5 \mathrm{~Hz}: \quad\left(F_{1,11}=17.853 ; \quad P=0.001\right.$ and $10 \mathrm{~Hz}: \quad\left(F_{1,14}=54.000\right.$; $P<0.001)$ stimulation frequencies. Post hoc tests demonstrated that infusions of the lower dose of galanin, in the absence of DPN stimulation, increased the number of BCM events $(0.15 \mathrm{nmol}$ : $P=0.003 ; 0.3 \mathrm{nmol} ; P=0.051$ ) during trial 2 (drug trial) compared to trial 1 (saline trial; Fig. 4A). Moreover, galanin facilitated BCM events after subthreshold DPN stimulation as male rats treated with either dose of galanin demonstrated significantly greater 

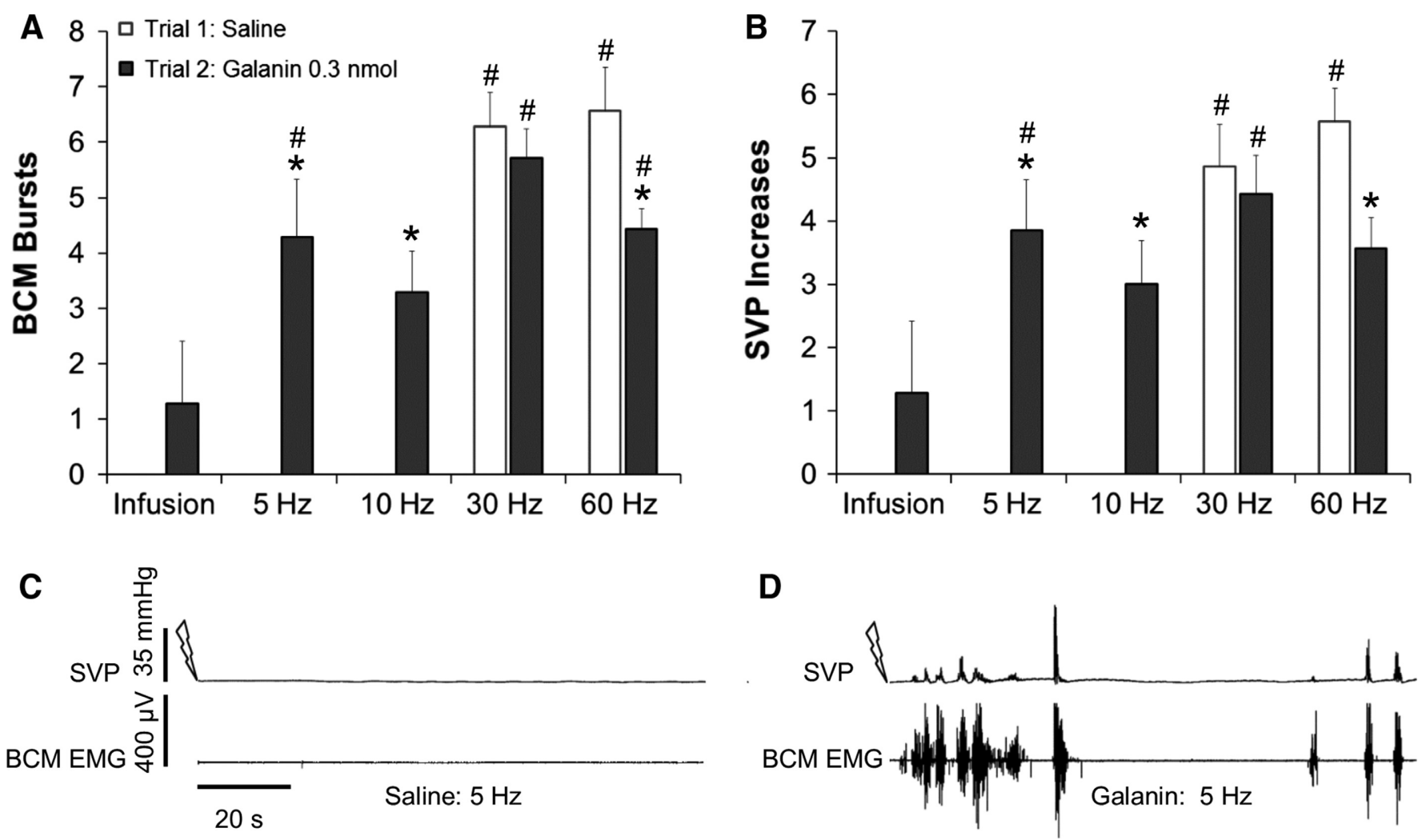

FIG. 5. Effects of galanin on the numbers of bulbocavernosus muscle (BCM) bursts and seminal vesicle pressure (SVP) increases in male rats. Quantitative analyses and accompanying electromyographic (EMG) traces of BCM bursts and SVP increases following intrathecal infusions of galanin. Quantitative analysis of BCM bursts (A) and SVP increases(B) in response to infusion, 5, 10, 30, and $60 \mathrm{~Hz}$ dorsal penile nerve (DPN) stimulations (counterbalanced) following intrathecal infusions of saline in trial 1 (control trial) or galanin $(0.3 \mathrm{nmol})$ in trial 2 (drug trial). EMG traces of $90 \mathrm{~s}$ duration following $10 \mathrm{~Hz}$ DPN stimulation (arrow) after an intrathecal infusion of saline (C: control trial) and galanin (D: same animals as in C). * denotes significant differences from trial 1 (control trial), while \# indicates significant differences from infusion, 5 and $10 \mathrm{~Hz}$ within the same testing trial.

numbers of BCM events following $10 \mathrm{~Hz}(0.15 \mathrm{nmol}: P<0.001$; 0.3 nmol: $P<0.001$; Fig. 4A) DPN stimulation. There was an effect of dosage for the $5 \mathrm{~Hz}$ stimulation frequency during trial 2 (drug trial). Specifically, animals treated with the higher dose of galanin demonstrated significantly greater numbers of BCM events following $5 \mathrm{~Hz}$ DPN stimulation compared to animals treated with the lower dose of galanin ( $0.3 \mathrm{nmol}: P=0.014$; Fig. 4A).

\section{BCM bursts}

The effects of galanin on BCM bursts were similar to the effects on BCM events. However, galanin infusions in the absence of DPN stimulation did not cause a significant increase in numbers of BCM bursts, even though it did increase BCM events. That is explained by the low portion of males that responded to galanin with at least one or more complete BCM bursts: only one rat responded in the high dose group. Hence, the effect of galanin infusions on ejaculatory reflexes without further DPN stimulation appears to be minor. In contrast, galanin had a stronger effect on facilitating BCM bursts induced by subthreshold DPN stimulation. There were main effects of testing trial on the numbers of $\mathrm{BCM}$ bursts for $5 \mathrm{~Hz}$ $\left(F_{1,11}=31.406 ; P<0.001\right)$ and $10 \mathrm{~Hz}\left(F_{1,11}=30.305 ; P<0.001\right)$ stimulation frequencies. There were also main effects of drug dosage for $5 \mathrm{~Hz} \quad\left(F_{1,11}=17.453 ; \quad P=0.002 ; \quad 10 \mathrm{~Hz}\right.$ : $\left(F_{1,11}=16.183 ; P=0.002\right)$ and $60 \mathrm{~Hz}\left(F_{1,11}=9.739 ; P=0.010\right)$ stimulation frequencies and significant interactions between the factors for $5 \mathrm{~Hz}\left(F_{1,11}=17.453 ; P=0.002\right), 10 \mathrm{~Hz}\left(F_{1,11}=16.183\right.$;
$P=0.002)$, and $30 \mathrm{~Hz}\left(F_{2,10}=6.119 ; P=0.018\right)$ stimulation frequencies. Post hoc tests revealed that the higher dose $(0.3 \mathrm{nmol})$ of galanin during trial 2 (drug trial) significantly increased the numbers of BCM bursts following $5 \mathrm{~Hz} \quad(P<0.001), \quad 10 \mathrm{~Hz}$ $(P<0.001), 30 \mathrm{~Hz}(P<0.001)$, and $60 \mathrm{~Hz}(P=0.049)$ stimulation frequencies compared to trial 1 (saline trial) (Fig. 4B-D). Male rats treated with the higher dose of galanin in trial 2 (drug trial: $0.3 \mathrm{nmol}$ ) had significantly more BCM bursts compared to the lower dose of galanin $(0.15 \mathrm{nmol})$ within trial 2 (drug trial; $5 \mathrm{~Hz}$ : $P<0.001 ; 10 \mathrm{~Hz}: \quad P<0.001 ; 30 \mathrm{~Hz}: \quad P=0.004 ;$ and $60 \mathrm{~Hz}$ : $P=0.006$; Fig. 4B).

Effects of galanin $(0.3 \mathrm{nmol})$ on SVP increases were tested in a second experiment, in a separate group of male rats with simultaneous recordings of SVP and BCM EMG (Fig. 5). The results confirmed the findings of the first galanin experiment described above and furthermore showed that infusions of galanin $(0.3 \mathrm{nmol})$ facilitated both the emission and expulsion components of ejaculation as shown in the increased numbers of BCM events, bursts, and SVP increases following subthreshold levels $(5-10 \mathrm{~Hz})$ of DPN stimulation. First, there were main effects of stimulation frequency on the numbers of BCM events (data not shown; $F_{4,24}=36.451$; $P<0.001$ ), bursts (Fig. 5A, C and D; $F_{4,24}=37.889 ; P<0.001$ ), and SVP increases (Fig. 5B, C and D; $F_{4,24}=18.603 ; P<0.001$ ). In saline-treated males, in trial 1 (saline trial), only 30 and $60 \mathrm{~Hz}$ DPN stimulation frequencies increased BCM events, bursts, and SVP increases as expected (all $P<0.001$ compared to saline infusion) (Fig. 5A and $\mathrm{B}$ ). There were also significant interactions 

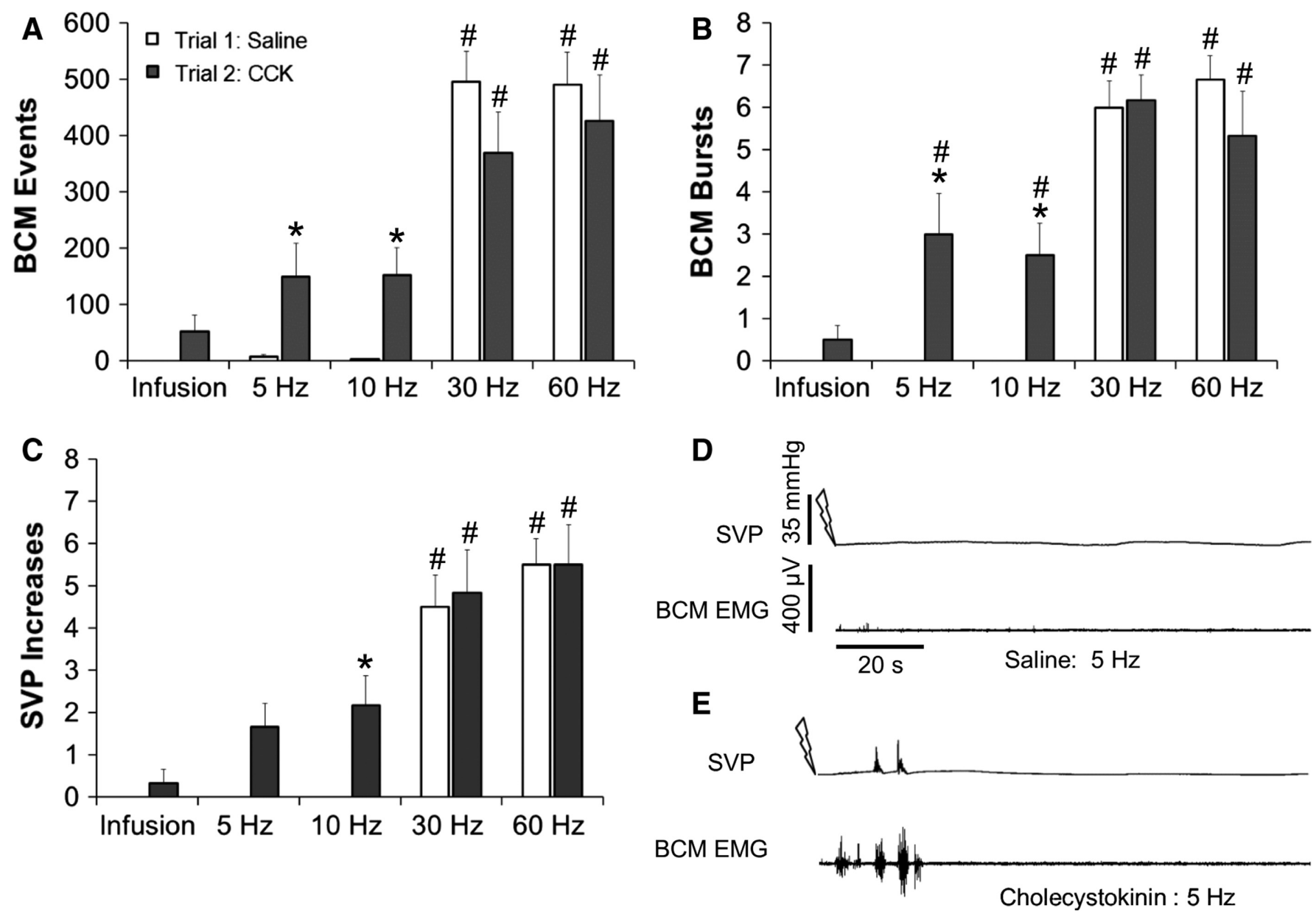

FIG. 6. Effects of cholecystokinin (CCK) on the numbers of bulbocavernosus muscle (BCM) events, bursts, and seminal vesicle pressure (SVP) increases in male rats. Quantitative analyses and accompanying electromyographic (EMG) traces of BCM events, bursts, and SVP increases following intrathecal infusions of CCK. Quantitative analysis of BCM events (A), bursts (B), and SVP increases (C) in response to infusion, 5, 10, 30, and $60 \mathrm{~Hz}$ dorsal penile nerve (DPN) stimulation (counterbalanced) following intrathecal infusions of saline in trial 1 (control trial) or CCK (4.35 nmol) in trial 2 (drug trial). EMG traces of $90 \mathrm{~s}$ duration following $5 \mathrm{~Hz}$ DPN stimulation (arrow) after an intrathecal infusion of saline (D: control trial) and CCK (E: same animals as in D). * denotes significant differences from trial 1 (control trial), while \# indicates significant differences from infusion, 5 and $10 \mathrm{~Hz}$ within the same testing trial.

between main factors of testing trial and stimulation frequency on the numbers of $\mathrm{BCM}$ events $\left(F_{4,24}=11.633 ; P<0.001\right)$, bursts $\left(F_{4,24}=10.774 ; \quad P<0.001\right)$, and SVP increases $\left(F_{4,24}=8.779\right.$; $P<0.001)$.

Post hoc analyses demonstrated that male rats treated with galanin in trial 2 (drug trial) had significantly greater numbers of BCM events (data not shown), bursts, and SVP increases following $5 \mathrm{~Hz}$ (events: $P<0.001$; bursts: $P<0.001$; Fig. 5 A, C, and D; SVP: $P<0.001$; Fig. 5B-D) and $10 \mathrm{~Hz}$ (events: $P=0.008$; bursts: $P=0.003$; Fig. 5A; SVP: $P=0.003$; Fig. 5B) DPN stimulation frequencies compared to trial 1 (saline trial). Overall, these results indicate that intrathecal galanin facilitates but does not trigger the emission and expulsion components of ejaculation. However, contrary to the first galanin experiment where it was found that intrathecal galanin facilitated numbers of BCM events and bursts not only in response to subthreshold $(5-10 \mathrm{~Hz})$ but also following threshold $(30-60 \mathrm{~Hz})$ levels of DPN stimulation, in this second experiment, threshold levels of DPN stimulation $(60 \mathrm{~Hz})$ significantly decreased the numbers of BCM bursts and SVP increases following galanin infusions in trial 2 (bursts: $P=0.041$; Fig. 5A; SVP: $P=0.036$; Fig. 5B).

\section{CCK facilitated BCM events, bursts, and SVPs}

In the final study, it was demonstrated that CCK (26-33) facilitated both the emission and expulsion components of ejaculation as demonstrated by the increased numbers of BCM events, bursts, and SVP increases following subthreshold levels of DPN stimulation. There were main effects of stimulation frequency on the numbers of BCM events $\left(F_{4,20}=51.540 ; \quad P<0.001\right)$, bursts $\left(F_{4,20}=56.316 ; P<0.001\right)$, and SVP increases $\left(F_{4,20}=38.292\right.$; $P<0.001$ ). As expected, during trial 1 (saline trial), infusions of saline and subthreshold DPN stimulations of 5 and $10 \mathrm{~Hz}$ did not increase BCM activity or SVP increases (Fig. 6A-C). In contrast, 30 and $60 \mathrm{~Hz}$ DPN stimulations increased the numbers of BCM events, bursts, and SVP increases compared to saline infusion, 5 and $10 \mathrm{~Hz}$ stimulation frequencies (all $P<0.001$; Fig. 6A-B). There were also significant interactions between main factors of testing trial and stimulation frequency on the numbers of $\mathrm{BCM}$ events $\left(F_{4,20}=4.897 ; \quad P=0.006\right)$ and bursts $\left(F_{4,20}=5.493\right.$; $P=0.004)$. Infusions of CCK in the absence of DPN stimulation did not have significant effects on BCM activity or SVP increases and only one rat responded with one or more BCM bursts to the 
CCK infusion. This result was similar to that described above for galanin infusions. However, CCK facilitated ejaculatory reflexes triggered by subthreshold DPN stimulation. Post hoc analyses revealed that after CCK infusions in trial 2 (drug trial), there were significantly greater numbers of $\mathrm{BCM}$ events, bursts, and SVP increases following $10 \mathrm{~Hz}$ (events: $P=0.040$; Fig. 6A; bursts: $P=0.011$; Fig. 6B; SVP: $P=0.005$; Fig. 6C) DPN stimulation in trial 2 (drug trial) compared to trial 1 (saline trial). CCK did not significantly affect SVP increases following $5 \mathrm{~Hz}$ DPN stimulation during trial 2 compared to trial 1 , even though BCM bursts and events were increased $(P=0.05$ and 0.001 ; Fig. 6B). Taken together, the results indicate that intrathecal infusions of CCK facilitate both the emission and expulsion components of ejaculatory reflexes following subthreshold levels of DPN stimulation in male rats.

\section{Discussion}

These data support the hypothesis that galanin and CCK receptor activation in LSt target areas is critical for ejaculatory reflexes in male rats by acting on galanin and CCK receptors in LSt target areas in the lumbosacral spinal cord. As predicted, intrathecal infusions of galanin or CCK receptor antagonists, galantide and proglumide respectively, severely disrupted both the emission and expulsion phases of ejaculation in response to sensory stimulation of the DPN in male rats. Conversely, galanin and CCK agonists facilitated ejaculatory reflexes following subthreshold sensory stimulation $(5-10 \mathrm{~Hz})$ in $100 \%$ of male rats. In contrast, galanin or CCK infusions in the absence of DPN stimulation were not sufficient to trigger ejaculatory reflexes. This finding is in contrast with our previous observations that agonists for GRP or mu opioid receptors do trigger ejaculatory reflexes in the absence of DPN stimulation (Kozyrev et al., 2012; Kozyrev \& Coolen, 2015). It is therefore possible that galanin and CCK act synergistically with the endogenous release of neuropeptides from LSt axon terminals, including GRP and enkephalin, upon sensory stimulation of the DPN.

Intrathecal infusions of galanin and CCK triggered ejaculatory reflexes in the absence of DPN stimulation only in few animals, which may potentially be explained by the presence of individual differences in galanin and CCK receptor densities in the lumbosacral spinal cord. It is possible that male rat 'responders' in the current study have a lower threshold to ejaculation and are more likely to exhibit the characteristic aspects of 'premature ejaculation'. Indeed, a previous study observed inherent differences in the spinal command of ejaculation between rats classified as 'rapid ejaculators' as compared to 'sluggish ejaculators' and 'normal ejaculators' based on their ejaculation frequency in a set of mating tests (Borgdorff et al., 2009). Specifically, BCM contractions following micro stimulation of the spinal ejaculation generator, corresponding to the expulsion phase of ejaculation, were significantly accelerated in 'rapid ejaculators' compared with 'sluggish ejaculators' and 'normal ejaculators' (Borgdorff et al., 2009). Overall, the agonist experiments in the current study indicate that activation of galanin and CCK receptors in the lumbosacral spinal cord facilitates ejaculatory reflexes following subthreshold levels of DPN stimulation $(5-10 \mathrm{~Hz})$ but is not sufficient to trigger ejaculatory reflexes in the majority of male rats in the absence of sensory stimulation of the DPN.

LSt cells and axons co-express galanin and CCK and the expression of both neuropeptides has been shown to be sexually dimorphic (Newton, 1992, 1993). Specifically, male rats have a significantly greater number of both galanin and CCK-ir neurons and greater optical densities for both galanin and CCK than female rats and males with a testicular feminization mutation (Tfm) that lack functional androgen receptors (Newton \& Phan, 2006). Therefore, androgens and functional androgen receptors regulate the expression of galanin and CCK in LSt cells. In addition, the expression of GRP, another neuropeptide expressed in LSt cells and axons (Kozyrev et al., 2012), has been shown to be androgendependent as castration significantly reduced the intensity of GRPir fibers in the lumbar spinal cord in male rats and this reduction was prevented by androgen replacement (Sakamoto et al., 2009). Galanin is a 29/30 amino acid long neuropeptide encoded by the GAL gene (Evans et al., 1993) that is widely distributed in the brain, spinal cord and gastrointestinal tract of mammals (Kask et al., 1997; Hokfelt et al., 1999) and is involved in a variety of physiological functions including feeding, nociception, cognition, regulation of blood pressure, and mood (Mechenthaler, 2008). Galanin-ir is expressed in dorsal root ganglion cells (Hokfelt et al., 1993; Kask et al., 1997; Landry et al., 2005), but in the lumbosacral spinal cord, is expressed exclusively in LSt cells (Truitt \& Coolen, 2002; Truitt et al., 2003; Staudt et al., 2011). Furthermore, galanin-ir axon terminals exclusively deriving from LSt cells are in close proximity to cell bodies and proximal dendrites of autonomic preganglionic and motor neurons (Newton, 1992; Ohmachi et al., 1996; Truitt \& Coolen, 2002). A predominately inhibitory, hyperpolarizing neuropeptide (Ito, 2009), galanin mediates its effects through its receptors: GALR1, GALR2, and GALR3. Galanin receptors are inhibitory G-protein-coupled receptors that are associated with G-protein coupled inwardly rectifying K+ (GIRK) channels (Kask et al., 1997; Wang et al., 1998) and GALR1 receptors have the highest densities postsynaptically compared to the other two receptor types (Brumovsky et al., 2006; Landry et al., 2006). In the lumbosacral spinal cord, GalR1 receptors have been observed in the dorsal and ventral horns, lateral spinal nuclei (Brumovsky et al., 2006) and numerous GALR1 positive mRNA neurons were detected in lamina $X$, presumably in the vicinity of the LSt cells (Brumovsky et al., 2006). GALR2 mRNA expression is considerably diminished compared to GALR1 mRNA expression and is confined primarily to the dorsal horn (Brumovsky et al., 2006). However, the most intensely labeled neurons are observed in the ventral horn, likely on motorneurons, and a few GALR2 positive mRNA neurons are detected in the sympathetic and parasympathetic lateral cell columns, in the locations of the IML and SPN (Brumovsky et al., 2006). In light of these findings, it is likely that galanin facilitates emission and expulsion by acting on GALR1 and GALR2 receptors in LSt target regions, specifically on autonomic preganglionic neurons in the lateral cell columns and on motorneurons in the ventral horns of the lumbosacral spinal cord in male rats. As previously mentioned, GALR1 receptors have been also observed in lamina $X$, in the region of LSt cells. However, it remains to be tested whether these receptors are expressed on LSt cells or other types of neurons in the lumbosacral spinal cord. If GALR1 receptors are indeed expressed on LSt cells, this suggests the possibility of autoreceptor interactions or reciprocal connections within the LSt cell population.

Similarly to galanin, CCK is one of the first peptide hormones to be isolated from the gastrointestinal tract and is widely distributed in the nervous system of mammals (Vanderhaeghen et al., 1975). CCK is involved in many physiological processes including digestion, satiety, and is known to induce anxiety and drug tolerance to opioids (Greenough et al., 1998; Fukazawa et al., 2007; Bowers 
et al., 2012; Yu \& Smagghe, 2014). The actions of CCK are mediated by two classes of receptors: CCKA and CCKB subtypes which belong to a family of G-protein-coupled receptors (Oz et al., 2007). CCK is expressed in dorsal root ganglia cells and is involved in the maintenance of neuropathic pain following nerve injury (Brewer et al., 2003; Kim et al., 2009) reflected in substantial increases in CCK mRNA following injuries to the CNS (Xu et al., 1993; Brewer et al., 2003). In the spinal cord, CCK is expressed in LSt cells and axons and CCK receptor expression has been described in motor neurons (Cortes et al., 1990; Schiffmann et al., 1991; Truitt et al., 2003). In addition, CCK depolarized neurons in lamina $X$ in the lumbar spinal cord (Phelan \& Newton, 2000), the precise location of LSt cells. Bath application of CCK has also been shown to depolarize isolated, hemisected lumbar spinal cord ventral horn neurons and motorneurons in neonatal rats (Suzue et al., 1981) and this depolarizing action was mediated by $\mathrm{CCKB}$ type receptors $(\mathrm{Oz}$ et al., 2007). Activation of postsynaptic CCKB receptors can enhance the excitability of motorneurons and other types of neurons in ventral spinal cord of rats (Oz et al., 2007). This may also be the mechanisms by which CCK facilitated BCM bursting.

CCK is an antagonist of endogenous opioids in the brain and spinal cord (Cesselin, 1995; Wiesenfeld-Hallin et al., 1999). It appears that CCK mediates its noxious effects through CCKB type receptors. The systemic administration of the CCKB receptor antagonist but not opioids, successfully reduced mechanical allodynia in an ischemic model of spinal cord injury (Xu et al., 1994). The tendency of CCK to antagonize opioids may explain why the effect of CCK infusions on ejaculatory reflexes following subthreshold sensory stimulation $(5-10 \mathrm{~Hz})$ was somewhat dampened compared to galanin infusions in this study. LSt cells are hypothesized to release their co-expressed neuropeptides, including enkephalin, onto neurons in their target regions, thereby triggering ejaculation. Indeed, our laboratory has demonstrated that intrathecal infusions of the mu opioid receptor agonist DAMGO consistently triggered ejaculatory reflexes in the absence of sensory stimulation in $75 \%$ of male rats (Kozyrev \& Coolen, 2015). Thus, activation of mu opioid receptors in the lumbosacral spinal cord was sufficient to trigger ejaculatory reflexes in a large majority of male rats. Infusions of CCK in the current study may have suppressed the facilitative effects of opioids on ejaculatory reflexes in male rats by antagonizing endogenous opioids released from the LSt cells onto target regions following stimulation of the DPN.

In the first set of experiments, the higher dose of galanin $(0.3 \mathrm{nmol})$ facilitated ejaculatory reflexes not only in response to subthreshold levels of DPN stimulation $(5-10 \mathrm{~Hz})$ but also following threshold stimulation frequencies $(30-60 \mathrm{~Hz})$. However, in the subsequent group of male rats, intrathecal infusion of the same dose of galanin (0.3 nmol; Fig. 5) significantly decreased numbers of BCM events, bursts, and SVP increases following $60 \mathrm{~Hz}$ DPN stimulation. In these animals, galanin $(0.3 \mathrm{nmol})$ facilitated numbers of BCM events, bursts, and SVP increases in response to subthreshold levels of DPN stimulation $(5-10 \mathrm{~Hz})$. The discrepancies in ejaculatory responses between the two groups of male rats suggest that galanin consistently facilitates ejaculatory reflexes to subthreshold $(5-10 \mathrm{~Hz})$ but not to threshold $(30-60 \mathrm{~Hz})$ levels of DPN stimulation. Similarly, the inhibition of ejaculatory reflexes demonstrated in the first galantide experiment was not completely identical in the second group of male rats. While the higher dose of galantide (10 nmol) completely suppressed ejaculatory reflexes (BCM events and bursts) in response to 30 and $60 \mathrm{~Hz}$ DPN stimulation frequencies in the first experiment, in the second (repeat) experiment performed in a separate group of animals in which the effects of galantide were tested on SVP increases, the same dose of galantide considerably attenuated but did not completely abolish ejaculatory reflexes. The differences in ejaculatory responses between the two groups of animals indicate that galantide consistently attenuates but not completely prevents ejaculatory reflexes in male rats.

As the activation of galanin or CCK receptors was not sufficient to trigger ejaculatory reflexes in the majority of male rats tested, the activation of galanin or CCK receptors may be required in combination with activation of other receptors in LSt target areas in order to trigger ejaculation. One candidate is the GRP receptor. Indeed, it was recently shown by our laboratory that activation of GRP receptors is required to trigger ejaculation and that intrathecal infusions of GRP triggered ejaculatory reflexes in up to $66 \%$ of male rats (Kozyrev et al., 2012).

Infusions of galanin significantly reduced the numbers of BCM events, bursts, and SVP increases following threshold DPN stimulation $(60 \mathrm{~Hz})$. This finding is in agreement with previous reports of intrathecal infusions of GRP, DAMGO, and deltorphin II that have all significantly reduced the numbers of BCM events, bursts, and SVP increases following $60 \mathrm{~Hz}$ DPN stimulation (Kozyrev \& Coolen, 2015). This consistent suppression of ejaculatory reflexes to threshold DPN stimulation $(60 \mathrm{~Hz})$ may be due to the effects of intrathecal infusions of neuropeptides combined with the endogenous release of opioids following DPN stimulation that cumulatively act to inhibit or desensitize the G-protein-coupled receptors in autonomic and motor regions involved in ejaculation and suppress the transmission of sensory inputs to the LSt cells which are required to trigger ejaculation.

In conclusion, these data support the hypothesis that activation of galanin and CCK receptors in the lumbosacral spinal cord is required for sensory stimulation-induced emission and expulsion in anesthetized and spinalized male rats. Galanin and CCK likely act on receptors in LSt cell target regions, including motorneurons in the SNB, and autonomic preganglionic neurons in the IML, CAN, and SPN in the lumbosacral spinal cord. Overall, these data suggest that the co-release of neuropeptides from LSt cell axon terminals including galanin, CCK, enkephalin, and GRP, triggers ejaculatory reflexes in male rats. Conversely, the release of only one of these neuropeptides is not sufficient to trigger ejaculatory reflexes in all animals in the absence of added sensory stimulation. Finally, these data suggest that galanin and CCK receptor antagonists or agonists may be promising pharmacological agents in the treatment of ejaculatory disorders, particularly for the purpose of delaying the onset of emission and expulsion in men suffering from premature ejaculation or facilitating ejaculation in men afflicted with an ejaculation, as following spinal cord injury (Kozyrev et al., 2016).

\section{Author contributions}

NK and LCM designed the experiments, conducted data analysis, and wrote the manuscript, NK collected all data.

\section{Conflict of interest}

Authors have no conflicts of interest to declare.

\section{Abbreviations}

BCM, bulbocavernosus muscle; CAN, central autonomic nucleus; CCK, cholecystokinin; DPN, dorsal penile nerve; EMG, electromyographic; GALR, galanin receptor; GRP, gastrin releasing peptide; IML, intermediolateral cell column; LSt, lumbar spinothalamic cells; SCI, spinal cord injury/spinal cord injured; SEG, spinal ejaculation generator; SNB, sacral nucleus bulbocavernosus; SVP, seminal vesicle pressure. 


\section{References}

Allard, J., Truitt, W.A., McKenna, K.E. \& Coolen, L.M. (2005) Spinal cord control of ejaculation. World J. Urol., 23, 119-126.

Borgdorff, A.J., Rossler, A.S., Clement, P., Bernabe, J., Alexandre, L. \& Giuliano, F. (2009) Differences in the spinal command of ejaculation in rapid ejaculating rats. J. Sex. Med., 6, 2197-2205.

Bowers, M.E., Choi, D.C. \& Ressler, K.J. (2012) Neuropeptide regulation of fear and anxiety: implications of cholecystokinin, endogenous opioids, and neuropeptide Y. Physiol. Behav., 107, 699-710.

Brewer, K.L., McMillan, D., Nolan, T. \& Shum, K. (2003) Cortical changes in cholecystokinin mRNA are related to spontaneous pain behaviors following excitotoxic spinal cord injury in the rat. Brain Res. Mol. Brain Res., 118, 171-174.

Brumovsky, P., Mennicken, F., O’Donnell, D. \& Hokfelt, T. (2006) Differential distribution and regulation of galanin receptors-1 and -2 in the rat lumbar spinal cord. Brain Res., 1085, 111-120.

Cesselin, F. (1995) Opioid and anti-opioid peptides. Fund. Clin. Pharmacol., 9, 409-433.

Chéhensse, C., Facchinetti, P., Bahrami, S., Andrey, P., Soler, J.M., Chrétien, F., Bernabé, J., Clément, P., et al. (2016) Human spinal ejaculation generator. Ann. Neurol., doi: 10.1002/ana.24819. [Epub ahead of print].

Clement, P. \& Giuliano, F.(2016) Physiology and pharmacology of ejaculation. Basic Clin. Pharmacol., 119(Suppl 3), 18-25

Clement, P., Peeters, M., Bernabe, J., Denys, P., Alexandre, L. \& Giuliano, F. (2008) Brain oxytocin receptors mediate ejaculation elicited by 7 hydroxy-2-(di-N-propylamino) tetralin (7-OH-DPAT) in anaesthetized rats. Brit. J. Pharmacol., 154, 1150-1159.

Coolen, L.M. (2005) Neural control of ejaculation. J. Comp. Neurol., 493, $39-45$.

Coolen, L.M., Veening, J.G., Wells, A.B. \& Shipley, M.T. (2003) Afferent connections of the parvocellular subparafascicular thalamic nucleus in the rat: evidence for functional subdivisions. J. Comp. Neurol., 463, 132-156.

Coolen, L.M., Allard, J., Truitt, W.A. \& McKenna, K.E. (2004) Central regulation of ejaculation. Physiol. Behav., 83, 203-215.

Cortes, R., Arvidsson, U., Schalling, M., Ceccatelli, S. \& Hokfelt, T. (1990) In situ hybridization studies on mRNAs for cholecystokinin, calcitonin gene-related peptide and choline acetyltransferase in the lower brain stem, spinal cord and dorsal root ganglia of rat and guinea pig with special reference to motoneurons. J. Chem. Neuroanat., 3, 467-485.

Evans, H., Baumgartner, M., Shine, J. \& Herzog, H. (1993) Genomic organization and localization of the gene encoding human preprogalanin. Genomics, 18, 473-477.

Fukazawa, Y., Maeda, T., Kiguchi, N., Tohya, K., Kimura, M. \& Kishioka, S. (2007) Activation of spinal cholecystokinin and neurokinin-1 receptors is associated with the attenuation of intrathecal morphine analgesia following electroacupuncture stimulation in rats. J. Pharmacol. Sci., 104, 159166.

Gerstenberg, T.C., Levin, R.J. \& Wagner, G. (1990) Erection and ejaculation in man. Assessment of the electromyographic activity of the bulbocavernosus and ischiocavernosus muscles. Brit. J. Urol., 65, 395-402.

Giuliano, F. (2011) Neurophysiology of erection and ejaculation. J. Sex. Med., 8, 310-315.

Giuliano, F., Pfaus, J., Srilatha, B., Hedlund, P., Hisasue, S., Marson, L. \& Wallen, K. (2010) Experimental models for the study of female and male sexual function. J. Sex. Med., 7, 2970-2995.

Greenough, A., Cole, G., Lewis, J., Lockton, A. \& Blundell, J. (1998) Untangling the effects of hunger, anxiety, and nausea on energy intake during intravenous cholecystokinin octapeptide (CCK-8) infusion. Physiol. Behav., 65, 303-310.

Hokfelt, T., Zhang, X., Verge, V., Villar, M., Elde, R., Bartfai, T., Xu, X.J. \& Wiesenfeld-Hallin, Z. (1993) Coexistence and interaction of neuropeptides with substance $\mathrm{P}$ in primary sensory neurons, with special reference to galanin. Regul. Peptides, 46, 76-80.

Hokfelt, T., Broberger, C., Diez, M., Xu, Z.Q., Shi, T., Kopp, J., Zhang, X., Holmberg, K. et al. (1999) Galanin and NPY, two peptides with multiple putative roles in the nervous system. Horm. Metab. Res., 31, 330-334.

Holmes, G.M. \& Sachs, B.D. (1991) The ejaculatory reflex in copulating rats: normal bulbospongiosus activity without apparent urethral stimulation. Neurosci. Lett., 125, 195-197.

Holmes, G.M., Chapple, W.D., Leipheimer, R.E. \& Sachs, B.D. (1991) Electromyographic analysis of male rat perineal muscles during copulation and reflexive erections. Physiol. Behav., 49, 1235-1246.

Ito, M. (2009) Functional roles of neuropeptides in cerebellar circuits. Neurosciences, 162, 666-672.
Kask, K., Berthold, M. \& Bartfai, T. (1997) Galanin receptors: involvement in feeding, pain, depression and Alzheimer's disease. Life Sci., 60, 15231533.

Kim, J., Kim, J.H., Kim, Y., Cho, H.Y., Hong, S.K. \& Yoon, Y.W. (2009) Role of spinal cholecystokinin in neuropathic pain after spinal cord hemisection in rats. Neurosci. Lett., 462, 303-307.

Kozyrev, N. \& Coolen, L.M. (2015) Activation of mu or delta opioid receptors in the lumbosacral spinal cord is essential for ejaculatory reflexes in male rats. PLoS One, 10, e 0121130

Kozyrev, N., Lehman, M.N. \& Coolen, L.M. (2012) Activation of gastrinreleasing peptide receptors in the lumbosacral spinal cord is required for ejaculation in male rats. J. Sex. Med., 9, 1303-1318.

Kozyrev, N., Staudt, M.D., Brown, A. \& Coolen, L.M. (2016) Chronic contusion spinal cord injury impairs ejaculatory reflexes in male rats: partial recovery by systemic infusions of dopamine D3 receptor agonist 7OHDPAT. J. Neurotraum., 33, 943-953.

Landry, M., Liu, H.X., Shi, T.J., Brumovsky, P., Nagy, F. \& Hokfelt, T. (2005) Galaninergic mechanisms at the spinal level: focus on histochemical phenotyping. Neuropeptides, 39, 223-231.

Landry, M., Bouali-Benazzouz, R., Andre, C., Shi, T.J., Leger, C., Nagy, F. \& Hokfelt, T. (2006) Galanin receptor 1 is expressed in a subpopulation of glutamatergic interneurons in the dorsal horn of the rat spinal cord. J. Comp. Neurol., 499, 391-403.

McKenna, K.E. \& Nadelhaft, I. (1986) The organization of the pudendal nerve in the male and female rat. J. Comp. Neurol., 248, 532-549.

Mechenthaler, I. (2008) Galanin and the neuroendocrine axes. Cell. Mol. Life Sci., 65, 1826-1835.

Newton, B.W. (1992) Galanin-like immunoreactivity in autonomic regions of the rat lumbosacral spinal cord is sexually dimorphic and varies with the estrous cycle. Brain Res., 589, 69-83.

Newton, B.W. (1993) Galanin immunoreactivity in rat spinal lamina IX: emphasis on sexually dimorphic regions. Peptides, 14, 955-969.

Newton, B.W. \& Phan, D.C. (2006) Androgens regulate the sexually dimorphic production of co-contained galanin and cholecystokinin in lumbar laminae VII and X neurons. Brain Res., 1099, 88-96.

Nicholas, A.P., Zhang, X. \& Hokfelt, T. (1999) An immunohistochemical investigation of the opioid cell column in lamina $\mathrm{X}$ of the male rat lumbosacral spinal cord. Neurosci. Lett., 270, 9-12.

Ohmachi, T., Nakamura, T., Zhang, F.Z., Tani, I. \& Takagi, H. (1996) Morpholological analyses of galaninergic inputs to the rat spinal parasympathetic nucleus. Exp. Brain Res., 109, 399-406.

Oz, M., Yang, K.H., Shippenberg, T.S., Renaud, L.P. \& O’Donovan, M.J. (2007) Cholecystokinin B-type receptors mediate a G-protein-dependent depolarizing action of sulphated cholecystokinin ocatapeptide (CCK-8s) on rodent neonatal spinal ventral horn neurons. J. Neurophysiol., 98, 11081114.

Phelan, K.D. \& Newton, B.W. (2000) Intracellular recording of lamina X neurons in a horizontal slice preparation of rat lumbar spinal cord. J. Neurosci. Meth., 100, 145-150.

Sakamoto, H., Takanami, K., Zuloaga, D.G., Matsuda, K., Jordan, C.L., Breedlove, S.M. \& Kawata, M. (2009) Androgen regulates the sexually dimorphic gastrin-releasing peptide system in the lumbar spinal cord that mediates male sexual function. Endocrinology, 150, 36723679 .

Schiffmann, S.N., Teugels, E., Halleux, P., Menu, R. \& Vanderhaeghen, J.J. (1991) Cholecystokinin mRNA detection in rat spinal cord motoneurons but not in dorsal root ganglia neurons. Neurosci. Lett., 123, 123-126.

Schroder, H.D. (1980) Organization of the motoneurons innervating the pelvic muscles of the male rat. J. Comp. Neurol., 192, 567-587.

Staudt, M.D., de Oliveira, C.V., Lehman, M.N., McKenna, K.E. \& Coolen, L.M. (2010) Activation of MAP kinase in lumbar spinothalamic cells is required for ejaculation. J. Sex. Med., 7, 2445-2457.

Staudt, M.D., de Oliveira, C.V., Lehman, M.N., McKenna, K.E. \& Coolen, L.M. (2011) Activation of NMDA receptors in lumbar spinothalamic cells is required for ejaculation. J. Sex. Med., 8, 1015-1026.

Staudt, M.D., Truitt, W.A., McKenna, K.E., de Oliveira, C.V., Lehman, M.N. \& Coolen, L.M. (2012) A pivotal role of lumbar spinothalamic cells in the regulation of ejaculation via intraspinal connections. J. Sex. Med., 9, 2256-2265.

Suzue, T., Yanaihara, N. \& Otsuka, M. (1981) Actions of vasopressin, gastrin releasing peptide and other peptides on neurons on newborn rat spinal cord in vitro. Neurosci. Lett., 26, 137-142.

Truitt, W.A. \& Coolen, L.M. (2002) Identification of a potential ejaculation generator in the spinal cord. Science, 297, 1566-1569. 
Truitt, W.A., Shipley, M.T., Veening, J.G. \& Coolen, L.M. (2003) Activation of a subset of lumbar spinothalamic neurons after copulatory behavior in male but not female rats. J. Neurosci., 23, 325-331.

Vanderhaeghen, J.J., Signeau, J.C. \& Gepts, W. (1975) New peptide in the vertebrate CNS reacting with antigastrin antibodies. Nature, 257, 604-605.

Veening, J.G. \& Coolen, L.M. (2014) Neural mechanisms of sexual behavior in the male rat: emphasis on ejaculation-related circuits. Pharmacol. Biochem. Be., 121, 170-183.

Wang, S., Hashemi, T., Fried, S., Clemmons, A.L. \& Hawes, B.E. (1998) Differential intracellular signaling of the GalR1 and GalR2 galanin receptor subtypes. Biochemistry, 37, 6711-6717.

Wiesenfeld-Hallin, Z., de Arauja Lucas, G., Alster, P., Xu, X.J. \& Hokfelt, T. (1999) Cholecystokinin/opioid interactions. Brain Res., 848, 78-89.
Xu, X.J., Puke, M.J., Verge, V.M., Wiesenfeld-Hallin, Z., Hughes, J. \& Hokfelt, T. (1993) Up-regulation of cholecystokinin in primary sensory neurons is associated with morphine insensitivity in experimental neuropathic pain in the rat. Neurosci. Lett., 152, 129-132.

Xu, X.J., Hao, J.X., Seiger, A., Hughes, J., Hokfelt, T. \& Wiesenfeld-Hallin, Z. (1994) Chronic pain-related behaviors in spinally injured rats: evidence for functional alterations of the endogenous cholecystokinin and opioid systems. Pain, 56, 271-277.

Young, B., Coolen, L. \& McKenna, K. (2009) Neural regulation of ejaculation. J. Sex. Med., 6(Suppl 3), 229-233.

Yu, N. \& Smagghe, G. (2014) CCK(-like) and receptors: structure and phylogeny in a comparative perspective. Gen. Comp. Endocr., 209, 74-81. 